\title{
Multitoxin analysis of Aspergillus clavatus-infected feed samples implicated in two outbreaks of neuromycotoxicosis in cattle in South Africa
}

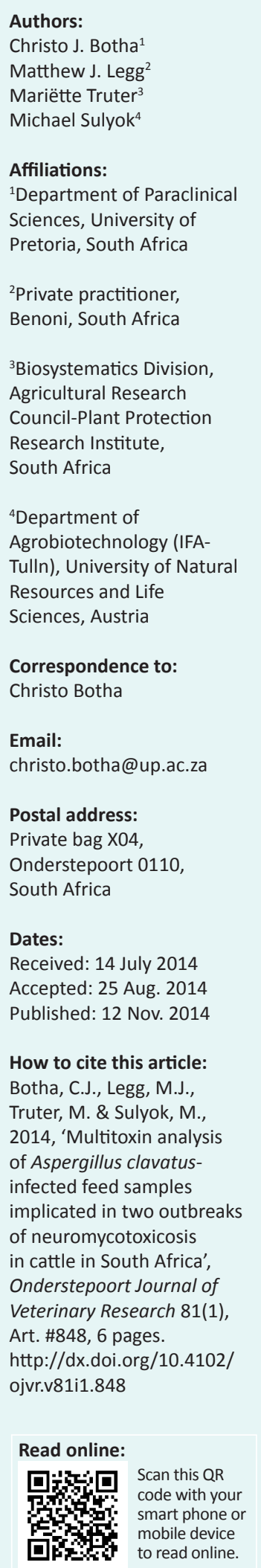

Aspergillus clavatus intoxication is a highly fatal neuromycotoxicosis of ruminants, especially cattle. It is caused by the ingestion of infected sprouting grain and sorghum beer residue. Locomotor disturbances, tremors and paralysis are observed. Histologically, degeneration and necrosis of larger neurons in the medulla oblongata, the midbrain, the thalamus and the ventral horns of the spinal cord are observed. Although a range of mycotoxins such as patulin, cytochalasin E and pseurotin A have been isolated, there is limited information on which specific mycotoxin or group of mycotoxins are involved during outbreaks of intoxication in livestock. In the present study, two outbreaks of A. clavatus poisoning in cattle are briefly described. Feed samples were collected for fungal identification, and culture and multitoxin analysis. A range of fungal metabolites were detected, and the estimated concentrations $(\mu \mathrm{g} / \mathrm{kg})$ are provided. Both the sprouting barley and brewer's grain were predominantly infected with $A$. clavatus and, to a lesser extent, Rhizopus arrhizus. The only common Aspergillus secondary metabolite present in all the samples was pseurotin A. Patulin and cytochalasin E were present in the sprouting barley samples, as well as the A. clavatus isolates cultured on malt extract agar for 2 weeks; however, neither of these mycotoxins could be detected in the brewer's grain sample.

\section{Introduction}

Ingestion of Aspergillus clavatus-infected feed may induce a highly fatal neuromycotoxicosis in ruminants, especially in cattle; however, sheep have also been poisoned (Gilmour et al. 1989; Kellerman et al. 2005; Riet-Correa et al. 2013; Schlosberg et al. 1991). This intoxication occurs sporadically in South Africa (Kellerman et al. 2005), but has also been reported in other countries (Riet-Correa et al. 2013; Sabater-Vilar et al. 2004; Schlosberg et al. 1991). Infected sprouting grains and malt are usually the cause, although, in South Africa, sorghum beer residue (maroek) has also been implicated. Aspergillus clavatus is a saprophytic fungus that often overgrows other fungal contaminants in the feed and is then visible as a greenish-blue mould (El-Hage \& Lancaster 2004; Kellerman et al. 1976; Kellerman et al. 1984).

The clinical signs of $A$. clavatus poisoning in cattle include: hypersensitivity, tremors (which are not consistently present), ataxia, progressive paresis and paralysis. Affected animals walk with a stiff-legged gait, take short steps and sometimes knuckle over at the fetlocks. They may stagger and fall before paralysis and death set in. Neurological signs that are not evident at rest can be precipitated following exercise. In addition, drooling of saliva and constipation have also been reported (El-Hage \& Lancaster 2004; Kellerman et al. 1976; Kellerman et al. 1984). Chronically affected cattle can survive for several weeks. There appears to be an extended latent period or a cumulative effect. During the experimental reproduction of this neurotoxicity, Kellerman and coworkers (1976) noted that cattle only became sick 7-10 days after commencement of feeding the poisonous ration or sorghum beer residue. El-Hage and Lancaster (2004) reported that new cases appeared up to 18 days after removal of infected sprouted barley.

Gross lesions are visible in the skeletal muscles of severely affected animals that exhibit clinical signs for longer periods (Kellerman et al. 2005). A greyish-white appearance of the larger muscles of the hindlimbs and forelimbs, especially near their origins and insertions, has been reported (Kellerman et al. 1976; Loretti et al. 2003; Riet-Correa et al. 2013). The most important microscopic lesions, which are also useful for diagnostic confirmation, occur in the brain and spinal cord. Degeneration and necrosis of larger neurons (chromatolysis and cytoplasmic vacuolation) in nuclei of the medulla oblongata, the midbrain, the thalamus and the ventral horns of the spinal cord have been described (Kellerman et al. 1976; Loretti et al. 2003). Furthermore, 
hyaline degeneration and necrosis of skeletal muscles and myocardial degeneration and necrosis have also been noted (Kellerman et al. 1976; Loretti et al. 2003).

Aspergillus clavatus synthesises mycotoxins such as: patulin (Lopez-Diaz \& Flannigan 1977); cytochalasin E (Büchi et al. 1973; Lopez-Diaz \& Flannigan 1977); tremorgenic metabolites such as tryptoquivalone (Clardy et al. 1975) and tryptoquivaline and its related toxic metabolites (Büchi et al. 1977; Clardy et al. 1975).

\section{Case histories}

\section{Case 1}

In November 2013, a group of young heifers and bulls exhibited neurological signs such as: knuckling over at the fetlocks (Figure 1), muscle fasciculation, hyperaesthesia, weakness of the hind quarters, ataxia, stumbling and recumbency. When handled, some collapsed and displayed mild seizure-like activity with paddling, but when left undisturbed were able to rise again. The farmer produced sprouting barley to feed the animals. The sprouting barley was heavily contaminated with fungi (Figure 2); two samples

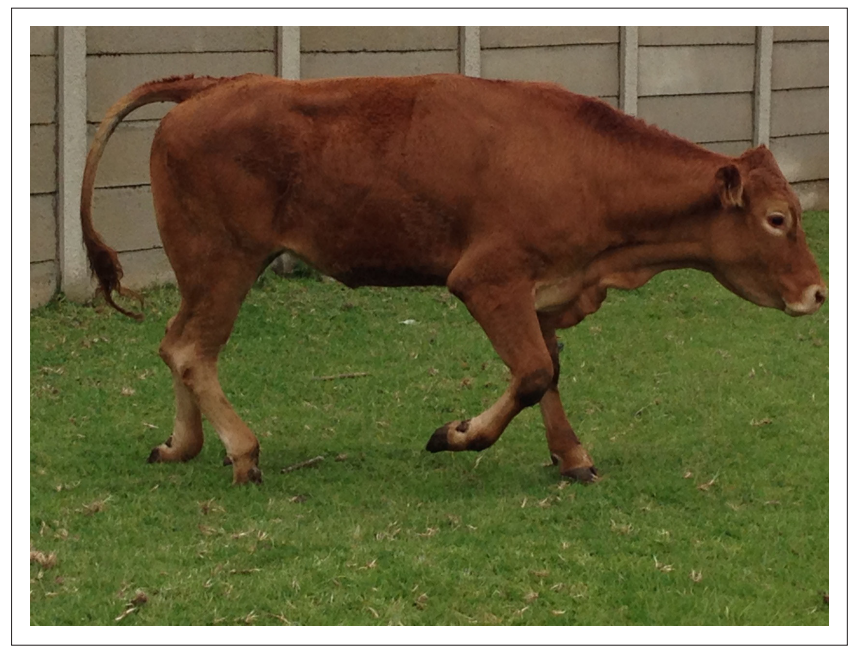

Source: Photo provided by authors

FIGURE 1: An affected heifer exhibiting flexion (over-knuckling) of the fetlocks.

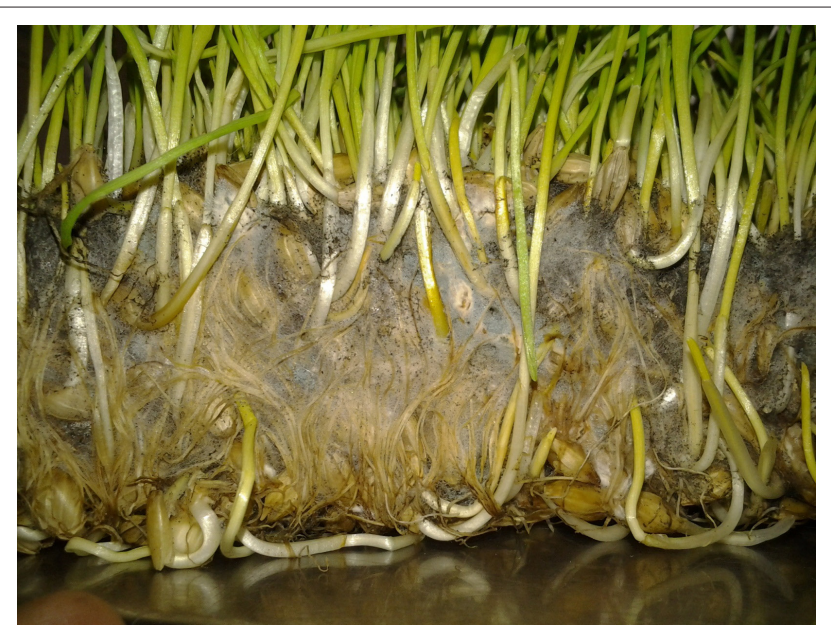

Source: Photo provided by authors

FIGURE 2: Aspergillus clavatus-infected sprouting barley. were collected and submitted for fungal identification and mycotoxicological analysis.

\section{Case 2}

In March 2014, 12 Friesland dairy cows died acutely after exhibiting moderate muscle tremor, aggressive behaviour and paralysis. The cows were fed a total mixed ration containing silage, brewer's grain, maize stover and a commercial concentrate. A set of tissue samples was collected and submitted for histopathology. Distinctive microscopic lesions in the central nervous system confirmed $A$. clavatus poisoning. Later, three animals became recumbent with the hindlimbs extended in an abnormal position behind them. Eventually, a total of 32 highly prized dairy cows succumbed. The brewer's grain and commercial pelleted ration were submitted for mycological identification and mycotoxicological screening.

There is limited information on which specific toxin or group of toxins are involved during outbreaks of intoxication (Lopez-Diaz \& Flannigan 1977; Sabater-Vilar et al. 2004). Although a range of mycotoxins have been isolated from toxic A. clavatus strains, none of the metabolites have been administered to ruminants in order to reproduce the intoxication (McKenzie et al. 2004). The objective of the present study was to submit feed samples implicated in the two recent outbreaks and A.clavatus isolates cultured from the barley for comprehensive screening for fungal metabolites.

\section{Materials and methods Fungal isolation}

Two sprouting barley samples from Case 1 and one brewer's grain sample and one commercial pelleted ration from Case 2, were visually inspected and isolations made directly from surface fungal growth by plating small clumps of fungal spores and/or mycelia onto potato dextrose agar (PDA) (Merck, Germany) amended with penicillin $(250 \mathrm{mg} / \mathrm{L})$. Isolations were also made from the plant material. Seeds $(n=25)$ and root segments $(n=25$, $10 \mathrm{~mm}$ long) from the sprouting barley and malt residue $(n$ = 50) from brewer's grain were surface disinfected with $1 \%$ sodium hypochlorite ( $3 \mathrm{~min}$ ), rinsed twice with sterile water, blotted dry and plated onto PDA amended with penicillin. Plates were incubated for 7-14 days, at $25^{\circ} \mathrm{C}$ under coolwhite fluorescent light. The plates were checked regularly and selected colonies were transferred to half-strength PDA. Isolates retrieved were identified based on culture and morphological characteristics. Aspergillus isolates were plated to Czapak Yeast Agar (CYA), Czapek Yeast Agar with 20\% Sucrose (CY20S) and Malt Extract Agar (MEA) (Klich 2002) and incubated in the dark at $25^{\circ} \mathrm{C}$ for 7 days. One plate of CYA was incubated at $37^{\circ} \mathrm{C}$ for 7 days. Rhizopus isolates were plated to PDA and MEA and incubated in the dark at $25^{\circ} \mathrm{C}$ and $37^{\circ} \mathrm{C}$ for 7 days (Schipper 1984). Selected singlespore isolates were deposited in the culture collection of the National Collections of Fungi, Biosystematics Division, Plant Protection Research Institute, Agricultural Research Council (ARC-PPRI), Pretoria, South Africa. 


\section{Mycotoxin analysis}

To comply with international phytosanitary regulations the feed samples collected from both outbreaks (Barley 1, Barley 2 and Brewers grain; Table 1) were air dried and finely milled before being shipped to Austria for multitoxin screening. In addition, two A. clavatus isolates (PPRI 13831 and PPRI 13832; Table 1) were also submitted for mycotoxin screening. A standardised extraction procedure was followed (Sulyok et al. 2006). Briefly: $5 \mathrm{~g}$ of each sample were extracted for $90 \mathrm{~min}$ with $20 \mathrm{~mL}$ of acetonitrile/water/acetic acid (79:20:1, v/v/v) on a rotary shaker (GFL 3017, GFL, Burgwedel, Germany). The crude extracts were diluted 1+1 $(\mathrm{v}+\mathrm{v})$ with acetonitrile/water/acetic acid (20:79:1, v/v/v) and $5 \mu \mathrm{L}$ of the diluted extract were injected.

Detection and quantification were performed with a liquid chromatography/tandem mass spectrometry (LC-MS/ MS) system (QTrap5500, Applied Biosystems, Foster City, California, United States of America) equipped with an electrospray ionisation (ESI) source (TurboIonSpray, Agilent Technologies, Waldbronn, Germany) and an ultra-high performance liquid chromatography system (1290 Series, Agilent Technologies, Waldbronn, Germany) (Malachova et al. 2014; Vishwanath et al. 2009). Chromatographic separation was performed at $25^{\circ} \mathrm{C}$ on a Gemini C18-column, $150 \mathrm{~mm}$ $\times 4.6 \mathrm{~mm}$ inner diameter (i.d.), $5 \mu \mathrm{m}$ particle size, equipped with a C18 security guard cartridge, $4 \mathrm{~mm} \times 3 \mathrm{~mm}$ i.d. (all from Phenomenex, Torrance, California, USA). Elution was carried out in binary gradient mode. Both mobile phases contained $5 \mathrm{mM}$ ammonium acetate and were composed of methanol/water/acetic acid 10:89:1 (v/v/v; eluent A) and 97:2:1 (v/v/v; eluent B), respectively. After an initial time of 2 min at $100 \%$ A, the proportion of B was increased linearly to $50 \%$ within $3 \mathrm{~min}$. Further linear increase of B to $100 \%$ within 9 min was followed by a hold-time of $4 \mathrm{~min}$ at $100 \%$ $\mathrm{B}$ and 2.5 min column re-equilibration at $100 \% \mathrm{~A}$. The flow rate was $1000 \mu \mathrm{L} / \mathrm{min}$. The ESI-MS/MS was performed in the scheduled multiple reaction monitoring (sMRM) mode both in positive and negative polarities in two separate chromatographic runs (Malachova et al. 2014; Vishwanath et al. 2009). The sMRM detection window of each analyte was set to the respective retention time $\pm 27 \mathrm{~s}$ and $\pm 42 \mathrm{~s}$ in positive and negative modes, respectively. The target scan time was set to 1s. Confirmation of positive analyte identification was obtained by the acquisition of two sMRMs per analyte (with the exception of moniliformin and 3-nitropropionic acid that each exhibit only one fragment ion), which yields 4.0 identification points according to commission decision 2002/657/EC (European Union 2002). Analyst ${ }^{\circledR}$ software version 1.5.1 (AB Sciex, Foster City, California, USA) was used to control the LC-MS/MS instrument, as well as for automatic and manual integration of the peak (Malachova et al. 2014; Vishwanath et al. 2009). Quantification of the > 300 metabolites included in the method was done based on linear, $1 / x$ weighed calibration curves derived from the analysis of serial dilutions of a multi-analyte stock solution. Results were not corrected for apparent recoveries.

\section{Results \\ Fungal identification}

Both the sprouting barley and brewer's grain were predominantly infected with $A$. clavatus and, to a lesser extent, Rhizopus arrhizus. In contrast, the commercial pelleted ration yielded only Rhizopus and no Aspergillus colonies. Plated plant material from the sprouting barley resulted in $70 \%$ A. clavatus and $50 \% R$. arrhizus colonies, whereas the brewer's grain resulted in $100 \%$ A. clavatus and $20 \%$ R. arrhizus colonies when plated on the respective agars. Several plant material segments were colonised by both fungi. Aspergillus clavatus isolates (PPRI 13831, 13832, 14650 and 14651) had colony diameters of $38 \mathrm{~mm}-42 \mathrm{~mm}$ on CYA, $40 \mathrm{~mm}-45 \mathrm{~mm}$ on MEA, $43 \mathrm{~mm}-48 \mathrm{~mm}$ on CY20S and $20 \mathrm{~mm}$ on CYA at $37^{\circ} \mathrm{C}$. Stipes were $500 \mu \mathrm{m}-1500 \mu \mathrm{m} \times 20 \mu \mathrm{m}-30 \mu \mathrm{m}$, smoothwalled, colourless, and expanding gradually into clavate vesicles, $50 \mu \mathrm{m}-75 \mu \mathrm{m}$ wide. Conidial zone extended from $50 \mu \mathrm{m}-150 \mu \mathrm{m}$ down from the top of the vesicles; heads were uniseriate with phialides $7 \mu \mathrm{m}-9 \mu \mathrm{m} \times 3.5 \mu \mathrm{m}$. Conidia were smooth-walled, ellipsoidal, $4 \mu \mathrm{m}-6 \mu \mathrm{m} \times 3 \mu \mathrm{m}-4 \mu \mathrm{m}$, and dull turquoise in mass. Colonies of $R$. arrhizus (PPRI 14572, only one isolate selected for preservation) were greyish brown. Rhizoids were brownish. Sporangiophores on stolons were up to $1500 \mu \mathrm{m}$ in length, up to $18 \mu \mathrm{m}$ in width, brown, single or aggregated in small groups. Sporangia were greyish black, powdery in appearance, up to $175 \mu \mathrm{m}$ in diameter. Sporangiospores were subglobose to ellipsoidal, with ridges on the surface, up to $8 \mu \mathrm{m}$ in length.

\section{Mycotoxin analysis}

The multitoxin screening results are tabulated (Table 1).

\section{Discussion}

Patulin is considered to be a major contributor to the neurotoxicity induced by A. clavatus (Sabater-Vilar et al. 2004). Riet-Correa et al. (2013) suggested that patulin analysis can aid in confirming a diagnosis of $A$. clavatus poisoning. In the current investigations, patulin was detected in the sprouting barley samples collected during the first outbreak and both isolates also synthesised this metabolite. The concentrations were considered to be high, as maximum tolerable levels ranging from $10 \mu \mathrm{g} / \mathrm{kg}-50 \mu \mathrm{g} / \mathrm{kg}$ have been set in the European Union for a range of apple-based and fruit-based commodities, including baby food (Commission Regulation $1881 / 2006)$. On the other hand, patulin could not be detected (< limit of detection [LOD]) in the brewer's grain sample collected during the second outbreak, despite histological confirmation of A. clavatus poisoning. Kellerman et al. (1976) could also not demonstrate patulin in toxic fractions isolated with column chromatography from an extract prepared from sorghum beer residue (maroek) collected during an outbreak in South Africa. However, despite mycological verification of A.clavatus contamination of the brewer's grain collected during the second outbreak, not all fungal strains are toxic, which might explain the absence of patulin in the sample (Loretti et al. 2003). Another common metabolite, cytochalasin 
TABLE 1: Fungal metabolites and estimated concentrations $(\mu \mathrm{g} / \mathrm{kg})$ in feed samples and Aspergillus clavatus isolates.

\begin{tabular}{|c|c|c|c|c|c|c|}
\hline \multirow[t]{3}{*}{ Analyte } & \multicolumn{5}{|c|}{ Samples } & \multirow[t]{3}{*}{ LOD } \\
\hline & \multicolumn{4}{|c|}{ Case 1} & \multirow{2}{*}{$\begin{array}{c}\text { Case 2: Brewer's } \\
\text { grain }\end{array}$} & \\
\hline & Barley 1 & Barley 2 & PPRI 13831 & PPRI 13832 & & \\
\hline Fumonisin $\mathrm{B}_{1}^{\mathrm{a}}$ & 1263 & 5107 & $<$ LOD & $<$ LOD & $<$ LOD & 6 \\
\hline Fumonisin $\mathrm{B}_{2}{ }^{\mathrm{a}}$ & 283 & 1384 & $<$ LOD & $<$ LOD & $<$ LOD & 2 \\
\hline Fumonisin $\mathrm{B}_{3}{ }^{\mathrm{a}}$ & 250 & 1362 & $<$ LOD & $<$ LOD & $<$ LOD & 4 \\
\hline Fumonisin $\mathrm{B}_{4}^{\mathrm{a}}$ & 389 & 1244 & $<$ LOD & $<$ LOD & $<$ LOD & 2 \\
\hline Deoxynivalenola $^{a}$ & $<$ LOD & 294 & $<$ LOD & $<$ LOD & $<L O D$ & 5 \\
\hline DON-3-glucoside & $<$ LOD & 12.5 & $<$ LOD & $<$ LOD & $<$ LOD & 0.1 \\
\hline Nivalenola $^{\mathrm{a}}$ & 6.45 & $<L O D$ & $<$ LOD & $<L O D$ & $<L O D$ & 0.8 \\
\hline Zearalenone-4-sulphate ${ }^{a}$ & NT & NT & $<L O D$ & $<$ LOD & $<$ LOD & 0.2 \\
\hline Zearalenone $^{a}$ & 195 & 53.4 & $<L O D$ & $<$ LOD & $<$ LOD & 0.2 \\
\hline$\alpha$-Zearalenol ${ }^{\mathrm{a}}$ & 7.18 & $<$ LOD & $<$ LOD & $<$ LOD & $<$ LOD & 0.5 \\
\hline$\beta$-Zearalenol ${ }^{a}$ & 28.0 & $<$ LOD & $<$ LOD & $<$ LOD & $<$ LOD & 0.5 \\
\hline Patulin ${ }^{a} \S$ & 504 & 728 & 30016 & 70784 & $<$ LOD & 75 \\
\hline Monoacetoxyscirpenol ${ }^{b}$ & 6.09 & $<$ LOD & $<$ LOD & $<$ LOD & $<$ LOD & 1.5 \\
\hline Moniliformin ${ }^{b}$ & 51.0 & $<$ LOD & $<$ LOD & $<$ LOD & $<$ LOD & 5 \\
\hline Enniatin $A^{b}$ & 98.3 & 10.0 & $<$ LOD & $<$ LOD & 4.31 & 0.02 \\
\hline Enniatin $\mathrm{A}_{1}{ }^{\mathrm{b}}$ & 47.7 & 15.8 & $<$ LOD & $<L O D$ & 20.13 & 0.02 \\
\hline Enniatin $\mathrm{B}^{\mathrm{b}}$ & 12.5 & 20.4 & $<L O D$ & $<L O D$ & 20.03 & 0.01 \\
\hline Enniatin $\mathrm{B}_{1}{ }^{\mathrm{b}}$ & 15.8 & 26.9 & $<$ LOD & $<L O D$ & 37.98 & 0.02 \\
\hline Beauvericin $^{\mathrm{b}}$ & 127 & 145 & $<L O D$ & $<L O D$ & 1 & 0.02 \\
\hline Fusarin $C^{b}$ & 7638 & 6356 & $<$ LOD & $<$ LOD & $<$ LOD & 5 \\
\hline Fusaric acid ${ }^{b}$ & 3754 & 29659 & $<$ LOD & $<$ LOD & $<$ LOD & 15 \\
\hline Fusarinolic acid ${ }^{b}$ & 8085 & 13344 & $<$ LOD & $<$ LOD & $<$ LOD & 15 \\
\hline Aurofusarin ${ }^{b}$ & 866 & 1076 & $<$ LOD & $<$ LOD & 18.39 & 1 \\
\hline Bikaverin $^{\mathrm{b}}$ & 19960 & 37463 & $<$ LOD & $<$ LOD & 15.23 & 1 \\
\hline Butenolide $^{b}$ & 12.6 & $<L O D$ & $<$ LOD & $<$ LOD & $<$ LOD & 10 \\
\hline Culmorin $^{\mathrm{b}}$ & 40.7 & 83.4 & $<$ LOD & $<$ LOD & $<$ LOD & 0.8 \\
\hline Equisetin ${ }^{b}$ & 337 & 202 & $<$ LOD & $<$ LOD & 8.47 & 0.15 \\
\hline Antibiotic $Y^{b}$ & 34.9 & $<$ LOD & $<$ LOD & $<$ LOD & $<$ LOD & 0.8 \\
\hline Apicidin $^{\mathrm{b}}$ & 1.47 & 49.4 & $<$ LOD & $<$ LOD & $<$ LOD & 2 \\
\hline Hydrolysed fumonisin $\mathrm{B}_{1}^{\mathrm{b}} \dagger$ & $<$ LOD & 220500 & $<$ LOD & $<$ LOD & $<$ LOD & 0.3 \\
\hline Siccanol ${ }^{\mathrm{b}} \uparrow$ & 18730 & 5758 & $<$ LOD & $<$ LOD & 4870 & NA \\
\hline Alternariol $^{c}$ & $<$ LOD & 7.72 & $<$ LOD & $<$ LOD & $<$ LOD & 0.6 \\
\hline Alternariolmethylether ${ }^{c}$ & 0.45 & 9.68 & $<$ LOD & $<$ LOD & 1.73 & 0.1 \\
\hline Macrosporin ${ }^{c}$ & $<$ LOD & $<$ LOD & $<$ LOD & $<$ LOD & 21.65 & 0.2 \\
\hline Infectopyron ${ }^{c}$ & 1549 & 752 & $<$ LOD & $<$ LOD & $<$ LOD & 4 \\
\hline Kojic acid ${ }^{d}$ & 113840 & 1006 & $<L O D$ & $<L O D$ & $<L O D$ & 10 \\
\hline 3-Nitropropionic acid ${ }^{d}$ & 76.3 & 24.5 & $<L O D$ & $<L O D$ & 6.77 & 1.2 \\
\hline Cytochalasin $\mathrm{E}^{\mathrm{d}} \S$ & 6791 & 6734 & 7560 & 7860.8 & $<$ LOD & 0.5 \\
\hline Pseurotin $A^{d} \S$ & 906 & 7727 & 1835.2 & 1148.3 & 50.30 & 1.5 \\
\hline Aspterric acid $^{d}$ & 233 & $<$ LOD & $<$ LOD & $<$ LOD & $<$ LOD & 5 \\
\hline Gliotoxin $^{d}$ & $<L O D$ & $<$ LOD & $<$ LOD & $<$ LOD & $<L O D$ & 2 \\
\hline Bis(methylthio)gliotoxin & $<$ LOD & $<$ LOD & $<L O D$ & $<L O D$ & $<L O D$ & 5 \\
\hline Tryptoquivaline $\mathrm{F}^{\mathrm{d}} \dagger$ & 26610 & 47460 & $<$ LOD & $<$ LOD & $<$ LOD & NA \\
\hline 15-dimethyl-2epi-fumiquinazolin $A^{d} \dagger$ & 50490 & 67300 & $<$ LOD & $<$ LOD & $<$ LOD & NA \\
\hline Fumiquinazoline $\mathrm{F}^{\mathrm{d} \dagger}$ & 20960 & 36080 & $<$ LOD & $<$ LOD & $<$ LOD & NA \\
\hline Griseofulvine & 122 & $<$ LOD & $<$ LOD & $<$ LOD & $<$ LOD & 0.2 \\
\hline Dechlorogriseofulvin ${ }^{e}$ & 118 & $<$ LOD & $<$ LOD & $<$ LOD & $<$ LOD & 0.2 \\
\hline Dihydrogriseofulvine & 42.6 & $<$ LOD & $<$ LOD & $<$ LOD & $<$ LOD & 0.2 \\
\hline Chaetoglobosin $\mathrm{A}^{\mathrm{e}} \uparrow$ & $<$ LOD & 153100 & 181000 & 205000 & $<$ LOD & 1 \\
\hline Roquefortine $\mathrm{C}^{\mathrm{e}}$ & 28.2 & 5.53 & $<$ LOD & $<$ LOD & $<$ LOD & 0.4 \\
\hline Curvularine & 5.74 & $<$ LOD & $<$ LOD & $<$ LOD & $<$ LOD & 0.3 \\
\hline Agroclavin $^{\mathrm{e}}$ & $<$ LOD & $<$ LOD & $<$ LOD & $<$ LOD & $<L O D$ & 0.1 \\
\hline
\end{tabular}

LOD, Limit of detection $(\mu \mathrm{g} / \mathrm{kg})$; $<\mathrm{LOD}$, below limit of detection; NT, not tested; NA, not available; PPRI, culture collection of the National Collections of Fungi, Biosystematics Division, Plant Protection Research Institute, Agricultural Research Council (ARC-PPRI), Pretoria, South Africa.

a, Major mycotoxins and derivatives; ${ }^{b}$, Fusarium metabolites; ${ }^{c}$, Alternaria metabolites; ${ }^{\mathrm{d}}$, Aspergillus metabolites; ${ }^{\mathrm{e}}$, Penicillium metabolites; ${ }^{\mathrm{f}}$, Metabolites from other fungal species; ${ }^{\mathrm{g}}$, Unspecified metabolites.

$\dagger$, Values denote peak area, as no standard is available; $¥$, isolates were cultured on malt extract agar for 2 weeks; $\S$, major Aspergillus clavatus metabolites. 
TABLE 1 (Continues...): Fungal metabolites and estimated concentrations $(\mu \mathrm{g} / \mathrm{kg}$ ) in feed samples and Aspergillus clavatus isolates.

\begin{tabular}{|c|c|c|c|c|c|c|}
\hline \multirow[t]{3}{*}{ Analyte } & \multicolumn{5}{|c|}{ Samples } & \multirow[t]{3}{*}{ LOD } \\
\hline & \multicolumn{4}{|c|}{ Case 1} & \multirow{2}{*}{$\begin{array}{c}\text { Case 2: Brewer's } \\
\text { grain }\end{array}$} & \\
\hline & Barley 1 & Barley 2 & PPRI 13831 & PPRI 13832 & & \\
\hline Fumitremorgin $\mathrm{C}^{\mathrm{e}}$ & NT & NT & $<$ LOD & $<$ LOD & 34.43 & NA \\
\hline Atpenin $\mathrm{A}_{5}{ }^{\mathrm{e}}$ & 0.38 & $<$ LOD & $<$ LOD & $<$ LOD & $<\mathrm{LOD}$ & 0.5 \\
\hline Trichodermin ${ }^{f}$ & 350 & 350 & $<$ LOD & $<$ LOD & $<$ LOD & 10 \\
\hline Brevianamide $\mathrm{F}^{\mathrm{g}}$ & 26.0 & 8.43 & 299.36 & 436.32 & 448.96 & 0.5 \\
\hline Rugulusoving & 48.1 & 18.7 & 198.72 & 260.16 & 779.2 & 0.3 \\
\hline Emoding & 33.7 & 41.9 & $<\mathrm{LOD}$ & $<$ LOD & 19.38 & 0.2 \\
\hline Tryptopholg $^{\mathrm{g}}$ & 4117 & 646 & $<$ LOD & $<$ LOD & 3376 & 15 \\
\hline
\end{tabular}

LOD, Limit of detection $(\mu \mathrm{g} / \mathrm{kg}) ;<$ LOD, below limit of detection; NT, not tested; NA, not available; PPRI, culture collection of the National Collections of Fungi, Biosystematics Division, Plant Protection Research Institute, Agricultural Research Council (ARC-PPRI), Pretoria, South Africa.

a, Major mycotoxins and derivatives; ${ }^{b}$, Fusarium metabolites; ${ }^{c}$, Alternaria metabolites; ${ }^{\mathrm{d}}$, Aspergillus metabolites; ${ }^{\mathrm{e}}$, Penicillium metabolites; ${ }^{\mathrm{f}}$, Metabolites from other fungal species; ${ }^{\mathrm{g}}$, Unspecified metabolites.

$\dagger$, Values denote peak area, as no standard is available; $\ddagger$, isolates were cultured on malt extract agar for 2 weeks; $\S$, major Aspergillus clavatus metabolites.

E, was present in the barley samples as well as the isolates, but was also below the limit of detection in the brewer's grain sample.

The only common Aspergillus secondary metabolite present in all the samples was pseurotin A, although at a comparatively lower concentration in the brewer's grain. At relatively high concentrations, pseurotin $\mathrm{A}$ is reported to be cytotoxic to cell lines (A2780 human ovarian carcinoma cells and rat pheochromocytoma cells [PC12 cells]). On the other hand, at lower concentrations it induces neurite outgrowth in PC12 cells. The authors concluded that pseurotin A may possess neuroprotective properties that may prevent or be useful to treat human diseases related to dysfunction of the nervous system such as senile dementia and Alzheimer's disease (Komagata et al. 1996). It is thus impossible to conclude that pseurotin A is involved in the neurotoxicity seen in cattle.

The tremorgenic compound, tryptoquivaline $\mathrm{F}$ was also present in the barley samples, but the concentration could not be determined, as no standard is available. No consistent pattern with respect to the presence of mycotoxins could be discerned when the incriminated feed samples collected during the two outbreaks were compared (Table 1).

Although mycological identification alone is usually insufficient to confirm a diagnosis and analytical tests are advisable, the question still remains as to which mycotoxin or combination of mycotoxins are involved. The specific mycotoxin or group of mycotoxins responsible for the neurotoxicity induced during these outbreaks could not be identified. Furthermore, when sampling feed for mycotoxin analysis, it should be remembered that the toxic portion of the feed could have all been consumed and mycotoxins are not homogeneously distributed in a feed sample (Sabater-Vilar et al. 2004).

In both cases investigated, the feed was overgrown by A. clavatus, possibly because this fungus grows and sporulates more aggressively. Flannigan (1986) reported that the optimum temperature and relative humidity for growth of A. clavatus is $20^{\circ} \mathrm{C}-35^{\circ} \mathrm{C}$ and $93 \%-98 \%$, respectively. Higher temperatures in the hydroponically cultivated barley sprouts will favour growth and $A$. clavatus will dominate the fungal population (Lopez-Diaz \& Flannigan 1977; McKenzie et al.
2004). At $25^{\circ} \mathrm{C}$, the synthesis of specifically cytochalasin $\mathrm{E}$ is favoured when compared to patulin production (LopezDiaz \& Flannigan 1977). In the first outbreak, the stock owner changed the process of producing sprouting barley. Where the hydroponically spouted barley was usually produced in trays in a refrigerated container, the batch implicated as the cause of the neurological signs was not produced in a refrigerated environment where the temperature and humidity could be controlled. The nutritional advantage of feeding sprouting grain produced hydroponically is doubtful (McKenzie et al. 2004). This practice is fraught with danger and livestock veterinarians should warn farmers about the risks of fungal contamination.

\section{Acknowledgement}

The authors would like to thank Dr Martin Ferreira, Potchefstroom, for information pertaining to the second outbreak. This work is based upon research supported by the National Research Foundation of South Africa. The LC-MS/ MS system was funded by the Federal Country Lower Austria and co-financed by the European regional development fund of the European Union.

\section{Competing interests}

The authors declare that they have no financial or personal relationship(s) that may have inappropriately influenced them in writing this article.

\section{Authors' contributions}

C.J.B. (University of Pretoria) was the principal investigator, M.J.L. (Private practitioner) investigated the first outbreak, M.T. (Agricultural Research Council-Plant Protection Research Institute) performed the mycological culturing and identification and M.S. (University of Natural Resources and Life Sciences) conducted the multitoxin analysis. All authors read and approved the final manuscript.

\section{References}

Büchi, G., Luk, K.C., Kobbe, B. \& Townsend, J.M., 1977, 'Four new mycotoxins of Aspergillus clavatus related to tryptoquivaline', Journal of Organic Chemistry 42, 244-246. http://dx.doi.org/10.1021/jo00422a015

Büchi, G., Kitaura, Y., Yuan, S.S., Wright, H.E., Clardy, J., Demain, A.L. et al., 1973, 'Structure of cytochalasin E, a toxic metabolite of Aspergillus clavatus', Journal of the American Chemical Society 95, 5423-5425. http://dx.doi.org/10.1021/ja00797a060 
Clardy, J., Springer, J.P., Koenig, T., Büchi, G., Matsuo, K. \& Wightman, R., 1975 'Tryptoquivaline and tryptoquivalone, two tremorgenic metabolites of Aspergillus
clavatus', Journal of the American Chemical Society 97, 663-665. http://dx.doi. org/10.1021/ja00836a045
clavatus, Journal of

Commission Decision of 12 August 2002 implementing Council Directive 96/23/ EC concerning the performance of analytical methods and the interpretation of results (2002/657/EC), viewed 10 December 2013, from http://eur-lex.europa. eu/LexUriServ/LexUriServ.do?uri=OJ:L:2002:221:0008:0036:EN:PDF

Commission Regulation 1881/2006/EC, 2006, 'Setting maximum levels of certain contaminants in foodstuffs', Brussels.

El-Hage, C.M. \& Lancaster, M.J., 2004, 'Mycotoxic nervous disease in cattle fed sprouted barley contaminated with Aspergillus clavatus', Australian Veterinary Journal 82, 639-641. http://dx.doi.org/10.1111/j.1751-0813.2004.tb12615.x

Flannigan, B., 1986, 'Aspergillus clavatus - an allergenic, toxigenic deteriogen of cereals and cereal products', International Biodeterioration 22, 79-89.

Gilmour, J.S., Inglis, D.M., Robb, J. \& Maclean, M., 1989, 'A fodder mycotoxicosis of ruminants caused by contamination of a distillery by-product with Aspergillus

clavatus', Veterinary Record 124, 133-135. http://dx.doi.org/10.1136/vr.124.6.133 and Mycotoxicoses of Livestock in Southern Africa, 2 nd edn., Oxford University Press, Cape Town.

Kellerman, T.S., Newsholme, S.J., Coetzer, J.A.W. \& Van der Westhuizen, G.C.A., 1984 'A tremorgenic mycotoxicosis of cattle caused by maize sprouts infested with Aspergillus clavatus', Onderstepoort Journal of Veterinary Research 51, 271-274.

Kellerman, T.S., Pienaar, J.G., Van der Westhuizen, G.C.A., Anderson, L.A.P. \& Naudé, T.W., 1976, 'A highly fatal tremorgenic mycotoxicosis of cattle caused by Asergillus clavatus', Onderstepoort Journal of Veterinary Research 43, 147-154.

Klich, M.A., 2002, Identification of Common Aspergillus Species, Centraalbureau voor Schimmelcultures, Utrecht.

Komagata, D., Fujita, S., Yamashita, N., Saito, S. \& Morino, T., 1996, 'Novel neuritogenic activities of pseurotin A and pannicillic acid', Journal of Antibiotics 49, 958-959. activities of pseurotin A and pannicillic acid',
http://dx.doi.org/10.7164/antibiotics.49.958

Lopez-Diaz, T.M. \& Flannigan, B., 1997, 'Production of patulin and cytochalasin E by Aspergillus clavatus during malting of barley and wheat', Internationa Journal of Food Microbiology 35, 129-136. http://dx.doi.org/10.1016/S01681605(96)01211-1
Loretti, A.P., Colodel, E.M., Driemeier, D., Corrêa, A.M., Bangel, J.J. \& Ferreiro, L., 2003, 'Neurological disorder in dairy cattle associated with consumption of beer residues contaminated with Aspergillus clavatus', Journal of Veterinary Diagnostic Investigation 15, 123-132. http://dx.doi.org/10.1177/104063870301500206

Malachova, A., Sulyok, M., Beltran, E., Berthiller, F. \& Krska, R., 2014, 'Optimization and validation of a quantitative liquid chromatography-tandem mass spectrometric method covering 295 bacterial and fungal metabolites including all regulated mycotoxins in four model food matrices', Journal of Chromatography A 1362, 145-156. http://dx.doi.org/10.1016/j.chroma.2014.08.037

McKenzie, R.A., Kelly, M.A., Shivas, RG., Gibson, J.A., Cook, P.J., Widderick, K. et al., 2004, 'Aspergillus clavatus tremorgenic neurotoxicosis in cattle fed sprouted grains', Australian Veterinary Journal 82, 635-638. http://dx.doi. org/10.1111/j.1751-0813.2004.tb12614.x

Riet-Correa, F., Rivero, R., Odriozola, E., De Lourdes Adrien, M., Medeiros, R.M.T. \& Schild, A.L., 2013, 'Mycoxicoses of ruminants and horses', Journal of Veterinary Diagnostic Investigation 25, 692-708. http://dx.doi. org/10.1177/1040638713504572

Sabater-Vilar, M., Maas, R.F.M., De Bosschere, H., Ducatelle, R. \& Fink-Gremmels, J. 2004, 'Patulin produced by an Aspergillus clavatus isolated from feed containing malting residues associated with a lethal neurotoxicosis in calttle', Mycopathologia 158, 419-426. http://dx.doi.org/10.1007/s11046-005-2877-x

Schipper, M.A., 1984, 'A revision of the genus Rhizopus', Studies in Mycology 25, 1-34.

Schlosberg, A., Zadikov, I., Perl, S., Yakobson, B., Varod, Y., Elad, D. et al., 1991 'Aspergillus clavatus as the probable cause of a lethal mass neurotoxicosis in sheep', Mycopathologia 114, 35-39. http://dx.doi.org/10.1007/BF00436689

Sulyok, M., Berthiller, F., Krska, R. \& Schuhmacher, R., 2006, 'Development and validation of a liquid chromatography/tandem mass spectrometric method for the determination of 39 mycotoxins in wheat and maize', Rapid Communications in Mass Spectrometry 20, 2649-2659. http://dx.doi.org/10.1002/rcm.2640

Vishwanath, V., Sulyok, M., Labuda, R., Bicker, W. \& Krska, R., 2009, 'Simultaneous determination of 186 fungal and bacterial metabolites in indoor matrices by liquid chromatography/tandem mass spectrometry', Analytical and Bioanalytical Chemistry 395, 1355-1372. http://dx.doi.org/10.1007/s00216-009-2995-2 